\title{
Dynamic Characteristics of the Rubber-Tailings Mixture Based on Dynamic Triaxial Test
}

\author{
Huandui Liu, ${ }^{1,2}$ Haiming Liu $\mathbb{D},{ }^{1,3}$ Wenyun Ding $\left(\mathbb{D},{ }^{4}\right.$ and Hongtao Xie $\mathbb{C}^{1}$ \\ ${ }^{1}$ Faculty of Civil Engineering and Mechanics, Kunming University of Science and Technology, Kunming, Yunnan 650224, China \\ ${ }^{2}$ State Key Laboratory of Geomechanics and Geotechnical Engineering, Institute of Rock and Soil Mechanics, \\ Chinese Academy of Sciences, Wuhan 430071, China \\ ${ }^{3}$ Key Laboratory of Earthquake Engineering and Engineering Vibration, Institute of Engineering Mechanics, \\ China Earthquake Administration, Harbin 150080, China \\ ${ }^{4}$ China Railway Eryuan Engineering Group Co. Ltd, Kunming, Yunnan 650011, China
}

Correspondence should be addressed to Haiming Liu; haiming0871@163.com

Received 18 October 2020; Revised 16 November 2020; Accepted 9 December 2020; Published 19 December 2020

Academic Editor: Shazim A. Memon

Copyright (c) 2020 Huandui Liu et al. This is an open access article distributed under the Creative Commons Attribution License, which permits unrestricted use, distribution, and reproduction in any medium, provided the original work is properly cited.

The liquefaction of tailings is a common failure mode under earthquake actions. The traditional treatment measures of waste rubber have the disadvantages of environmental pollution and occupying soil resources. The combined treatment of waste rubber and tailings is very likely to have important engineering application and theoretical value, and the dynamic characteristics of the rubber-tailings mixture (RTM) are essential and indispensable for handling them together. In this paper, the dynamic triaxial test was used to study the dynamic mechanical characteristics of the RTM. The test was divided into 5 groups with 54 valid samples. The effects of the rubber particle size, rubber content, consolidation pressure, $\mathrm{pH}$ value, and soaking time on the dynamic characteristics of the RTM were studied and discussed. The results show that the liquefaction cycle number of the RTM is $50 \%$ higher than that of tailings, and the particle cluster effect theory of the RTM is put forward. It will provide a theoretical basis and guidance for the treatment of the waste rubber and tailings.

\section{Introduction}

The tailings dam is an artificial dangerous debris flow with high potential energy. China's tailings dam is not only large in quantity but also small in scale and is widely distributed. At present, most of the tailings are disposed of by stacking tailings dam. However, due to the poor dynamic characteristics and low liquefaction resistance of tailings material, the dam break disasters or related accidents of tailings dam occur frequently under earthquake actions [1]. By November 2015, the total amount of tailings in use or untreated only in China exceeded 20 billion tons [2]. Consequently, the safe and effective treatment measures of tailings have important engineering application value.

With the rapid development of the global economy, the number of waste rubbers is quickly increasing. According to statistics, $5 \times 10^{6}$ tons of waste rubber are produced every year in the world [3]. Waste rubber occupies a lot of land resources, destroys vegetation growth, and easily leads to fire [4]. Furthermore, waster rubber has strong heat resistance, mechanical abrasion resistance, and corrosion resistance, which will cause long-term harm to the environment [5]. The rubber particles made from waste rubber have the characteristics of low relative density, high water permeability, high elastic deformation, and high damping ratio [6]. The rubber particles can absorb seismic load under earthquake load. However, the deformation modulus of rubber particles is low and the bearing capacity is insufficient. If rubber particles are mixed with tailings, the dynamic characteristics of rubber-tailings mixture (RTM) may be greatly improved, which can be widely and extensively used in the retaining wall, road subgrade, and airport runway [7].

Considering the similarity of mechanical properties between tailings and sand, this paper reviews the research 
progress of the RTM from the characteristics of rubber-sand mixtures (RSM). In recent years, the mechanical properties of the RSM have been widely investigated by scholars. Figure 1 shows the research paper related to the RSM publications on Web of Science, in which the search keywords are two titles, rubber and sand, and the logical relationship is "and." It can be seen from Figure 1 that the research on RSM is in a trend that constantly moves upward. Lee et al. [8], Wang et al. [9], and Edil and Bosscher [10] had proved that the RSM could be used in the retaining wall, Earth fill, and highway base on the triaxial test, constant head permeability test, consolidated drainage triaxial test, and large-scale direct shear test. Cristine [11] proved that the addition of rubber could reduce the cost and displacement of the retaining wall. Moghaddas and Norouzi [12] obtained the best ratio, thickness, and buried depth of cushion of the RSM through the bearing capacity test. Panjamani and Manohar [13] proved that the peak strength, brittleness index, and energy consumption capacity of the RSM could be increased to about 25\% through the direct shear test and triaxial test. Pamukcu and Akbulut [14] showed that the addition of rubber particles increased the damping ratio of pure sand by conducting torsional resonance column tests of the RSM. Marto et al. [15] attested that adding rubber particles into sand could effectively improve its shear properties through the direct shear test of the RSM. Abdelhaleem and Lotfy [16] and Hazarika et al. [17] revealed that the RSM could effectively improve resistant seismic load, increase the natural period of site soil, inhibit low cycle action under seismic, and reduce the residual displacement under seismic action through the vibrating table tests and other studies. Okur and Umu [18] discussed the effects of the relative size and proportion of the rubber on the dynamic characteristics of the RTM and developed semiempirical relationships to determine the cyclic characteristics of the RTM. Conducting the torsional resonance column tests and dynamic triaxial tests of rubber soil and RSM, Anastasiadis et al. $[19,20]$ stated that the shear modulus and damping ratio of the RTM were significantly affected by the content of rubber and the relative size of rubber to soil particles. Furthermore, Anastasiadis et al. [21], Ehsani et al. [22], Zheng and Sutter [23], and Bahador and Manafi [24] showed that the shear modulus decreased and the damping ratio increased with the content of rubber particle.

Although the mechanical properties of tailings and sand are similar, there are great differences between them. The tailings material is particles of original rock ore after crushing and grinding. Compared with the original rock, the size and shape of tailings particles are greatly different in the process of mining engineering. Contrasted with the natural sand, the tailings material has great differences in the particle size, particle shape, and particle distribution, because the tailings material has undergone acid washing and other operations in the process of mineral extraction. According to the above research, there are many researches on the RSM but few reports on the RTM. The RTM is likely to be used as a subgrade filler and other related projects. Nonetheless, the tailings are often acidic, which may affect the mechanical characteristics of the

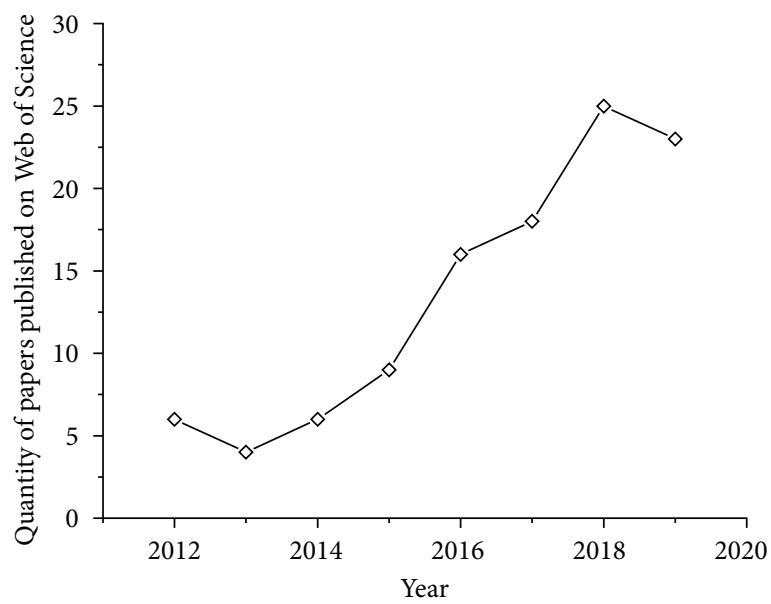

FIgURE 1: The trend chart of SCI papers on the RSM.

RTM. Therefore, it is of great engineering application and theoretical value to study the dynamic characteristics of the RTM under the influence of multiple factors.

In this research, the dynamic characteristics of the RTM under different effects, namely, the rubber particle size, rubber particle content, consolidation pressure, $\mathrm{pH}$ value, and acid immersion time, were analyzed by the dynamic triaxial test. The mechanism of its change law is elaborated, and the particle cluster effect is proposed. It is of great significance to improve the dynamic characteristics of tailings, reduce the occurrence of disasters, and realize the reuse of waste rubber.

\section{Experimental Program}

2.1. Material. The tailings selected in this experiment are from Kafang tailings pond in Gejiu of Yunnan Province, belonging to tin tailings. The particle-size distribution chart of tailings is shown in Figure 2, in which the nonuniformity coefficient $C_{u}$ is 2.80 , and the curvature coefficient $C_{c}$ is 0.85 . The pore ratio of tailings $e$ is 0.92 , the specific density $G_{s}$ is 3.07 , and the vertical permeability coefficient $k_{v}$ is $2.3 \times 10^{-6} \mathrm{~m} / \mathrm{s}$. The scanning electron microscope of tailings is shown in Figure 3.

The rubber particles were provided by Huayi Rubber Co., Ltd., and were made from waste tires by multistep crushing. The bulk density of rubber particles was about $0.75 \mathrm{~g} / \mathrm{cm}^{3}$ and the relative density was $1.13 \mathrm{~g} / \mathrm{cm}^{3}$. Four kinds of rubber particles-called CR1, CR2, CR3, and Cr4-were prepared. The size of rubber particles CR1 was from $3.35 \mathrm{~mm}$ to $4 \mathrm{~mm}$, that of CR2 was from $1.18 \mathrm{~mm}$ to $2 \mathrm{~mm}$, that of $\mathrm{Cr} 3$ was from $0.60 \mathrm{~mm}$ to $0.85 \mathrm{~mm}$, and that of $\mathrm{Cr} 4$ was from $0.18 \mathrm{~mm}$ to $0.25 \mathrm{~mm}$.

2.2. Experimental Procedure. This test mainly studied the dynamic characteristics of the RTM under multiple effects, namely, rubber particle content, rubber particle size, consolidation pressure, $\mathrm{pH}$ value of the soaked solution, and acid soaking time. The test scheme was shown in Table 1. 


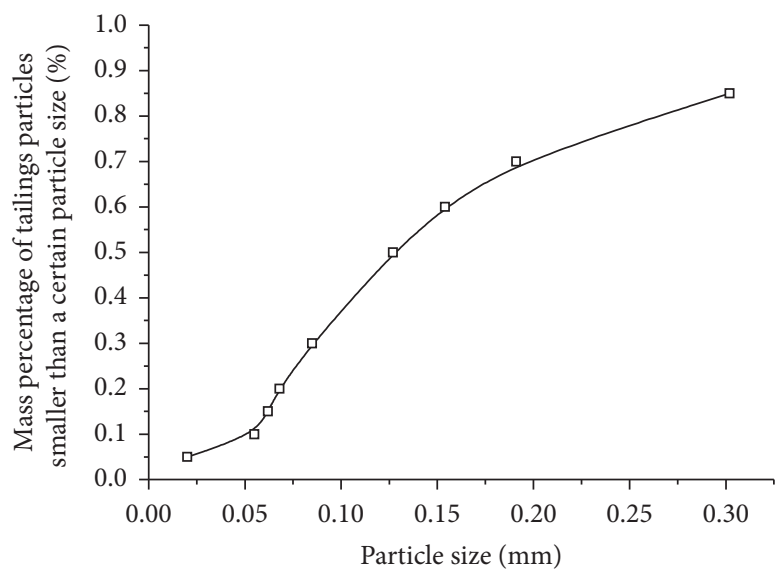

Figure 2: The particle-size distribution chart of Kafang tailings.

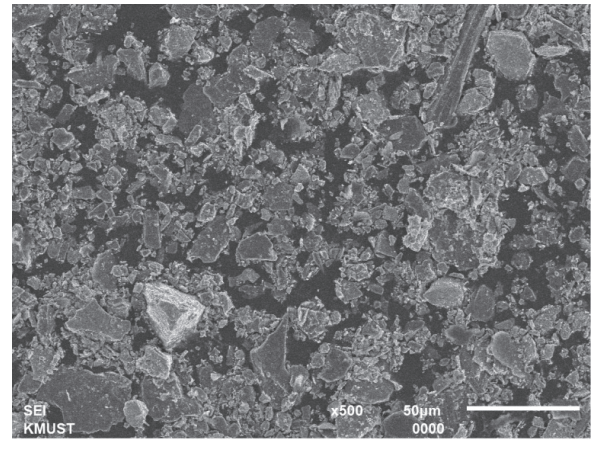

(a)

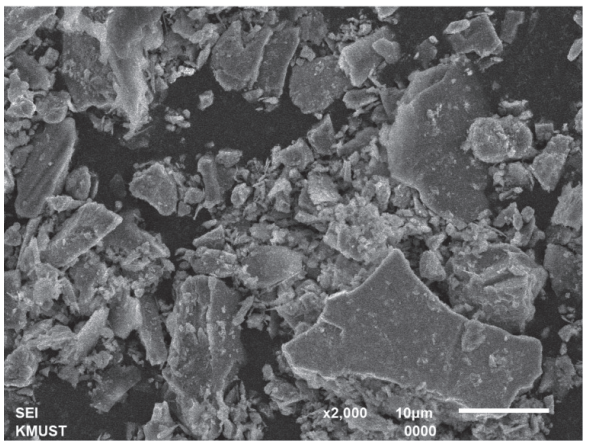

(b)

Figure 3: The scanning electron microscope of tailings particles.

TABLE 1: The table of test samples for each variable.

\begin{tabular}{|c|c|c|c|c|c|}
\hline $\begin{array}{l}\text { Label of } \\
\text { experimental } \\
\text { sample }\end{array}$ & $\begin{array}{l}\text { Rubber particle } \\
\text { content }(\%)\end{array}$ & $\begin{array}{l}\text { Rubber particle } \\
\text { size }(\mathrm{mm})\end{array}$ & $\begin{array}{l}\text { Consolidation } \\
\text { pressure }(\mathrm{kPa})\end{array}$ & $\begin{array}{c}\mathrm{pH} \text { value of } \\
\text { soaked solution }\end{array}$ & $\begin{array}{l}\text { Acid soaking } \\
\text { time }(\mathrm{d})\end{array}$ \\
\hline RT1 & 0 & \multirow{4}{*}{$2-1.18$} & \multirow{4}{*}{100} & \multirow{4}{*}{7} & \multirow{4}{*}{28} \\
\hline RT2 & 5 & & & & \\
\hline RT3 & 15 & & & & \\
\hline RT4 & 35 & & & & \\
\hline RT3 & \multirow{4}{*}{15} & $4-3.35$ & \multirow{4}{*}{100} & \multirow{4}{*}{7} & \multirow{4}{*}{28} \\
\hline RT5 & & 2-1.18 & & & \\
\hline RT6 & & $0.85-0.60$ & & & \\
\hline RT7 & & $0.25-0.18$ & & & \\
\hline RT3 & \multirow{3}{*}{15} & \multirow{3}{*}{$2-1.18$} & 100 & \multirow{3}{*}{7} & \multirow{3}{*}{28} \\
\hline RT8 & & & 150 & & \\
\hline RT9 & & & 200 & & \\
\hline RT10 & \multirow{4}{*}{15} & \multirow{4}{*}{$2-1.18$} & \multirow{4}{*}{100} & 1 & \multirow{4}{*}{28} \\
\hline RT11 & & & & 2 & \\
\hline RT12 & & & & 3 & \\
\hline RT3 & & & & 7 & \\
\hline RT13 & \multirow{4}{*}{15} & \multirow{4}{*}{$2-1.18$} & \multirow{4}{*}{100} & \multirow{4}{*}{2} & 3 \\
\hline RT14 & & & & & 7 \\
\hline RT15 & & & & & 14 \\
\hline RT12 & & & & & 28 \\
\hline
\end{tabular}

Note. The content of rubber particles in the RTM is the volume ratio content. 
2.3. Sample Preparation. Before mixing rubber particles with tailings, due to the existence of some small bubbles and hydrophobic layers, the rubber particles floated on the water surface and were difficult to reach the saturation state. In order to shorten the saturation time of rubber particles and improve the saturation effect, the rubber particles were rubbed in water every other day to drive out the bubbles as soon as possible.

For the samples from RT10 to RT15, the rubber particles were soaked in the acid solution with predetermined $\mathrm{pH}$ value and kneaded in water to make the rubber particles reach the saturation state, as shown in Figure 4. After the predetermined soaking time was reached, the rubber particles were repeatedly rubbed in distilled water with $\mathrm{pH}=7$, and the pure water was continuously replaced to make the $\mathrm{pH}$ value of rubber particles reach 7 .

The rubber particles and tailings were vacuum-saturated in distilled water for $24 \mathrm{~h}$. The wet ramming method was used to make the specimen [25]. The rubber and tailings were mixed and stirred manually for $5 \mathrm{~min}$ to reach the uniform state. Then they were put into the sample mold for vibration and sample preparation. The $B$ value of the sample must be above 0.96 during the saturation process of the testing machine to make the sample reach the saturation state.

2.4. Experiment Instrument. The electromagnetic vibration triaxial test system, whose type is DDS-70, is used in this experiment, as shown in Figure 5. The axial pressure is less than or equal to $120 \mathrm{~N}$, and the load frequency is less than or equal to $60 \mathrm{~Hz}$. Peng et al. measured the seismic-time curve and analyzed its frequency spectrum characteristics. It was demonstrated that the dominant frequency of earthquake was about $1.4-7.25 \mathrm{~Hz}$, while the fundamental frequency was about $1 \mathrm{~Hz}$ [26]. According to the field measured data of traffic load, the vibration frequency is constantly changing [27]. Combined with the range of test instruments, the test load adopts a sine wave with the frequency of $10 \mathrm{~Hz}$. Zhang and Wang [28] carried out tests with saturated standard coarse sand at different frequencies from $1 \mathrm{~Hz}$ to $20 \mathrm{~Hz}$, which showed that the same liquefaction effect could be obtained by long vibration time at low frequency and short vibration time at high frequency. The vibration frequency has a significant influence on the development of axial strain during the vibration process of saturated dense sand [29]. The increase of frequency will reduce the axial strain of sand during liquefaction. Different vibration frequency will change the growth rate of axial strain with time and vibration number before liquefaction and affect the relationship between axial strain ratio and vibration number ratio [30].

\section{Effects of Rubber Crumbs on the Resistance to Liquefaction of Tailings}

3.1. Effects of Particle Size of the Rubber. The displacementtime curve of the RTM is shown in Figure 6. The displacement time can be divided into three stages. The first

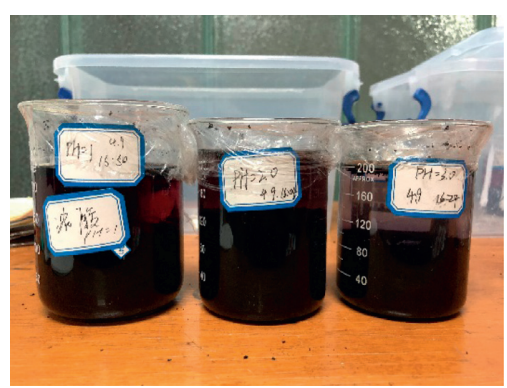

FIGURE 4: Some pictures of rubber particles soaked in acid solution.

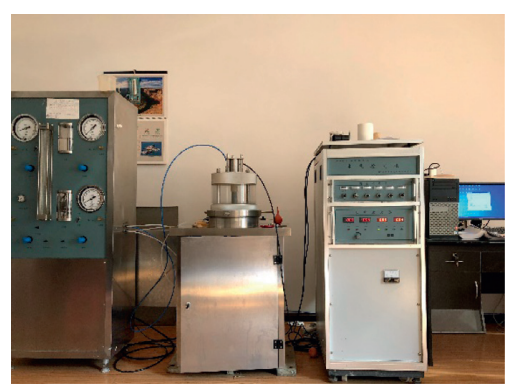

FIgURE 5: The electromagnetic vibration triaxial test system: type DDS-70.

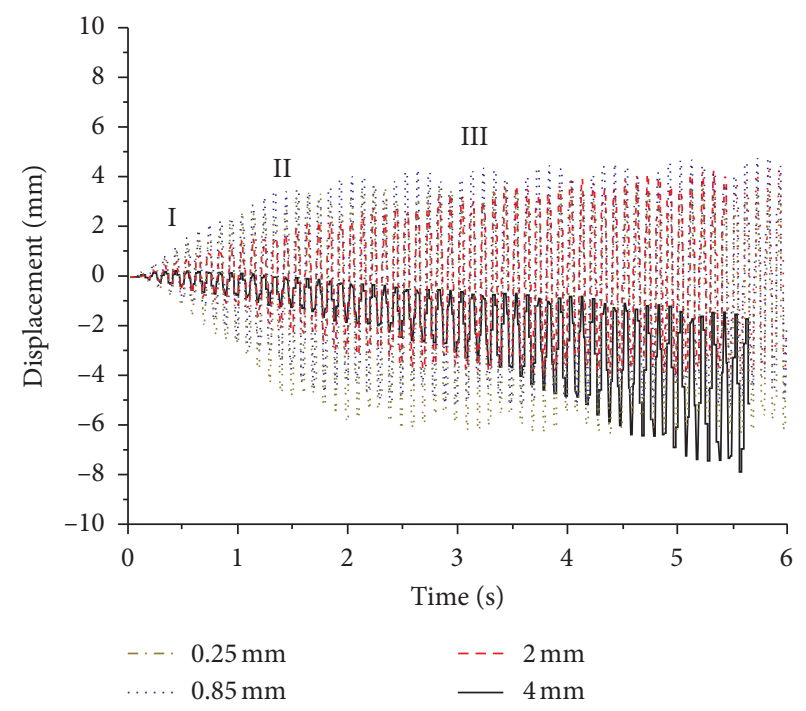

Figure 6: The displacement-time diagram under different rubber particle size.

stage is called stage I-deformation oscillation-in which there is no large deformation. The second stage is called stage II-deformation aggravation-in which the deformation increases rapidly and the deformation speed is fast. The third stage is called stage III-stability stage-in which the deformation is stable and the deformation increment is small. It can be seen that stage I is not obvious, but stage II and stage III are more conspicuous. Compared with the displacement-time diagram of the test, it can be seen that the time required for stage II gradually increases, and the transition of stage II and stage III 
gradually slows down as the size of rubber particles increases.

The diagram between pore water pressure and time of the RTM is shown in Figure 7. The accumulation rate of pore water pressure gradually slows down with the increase of rubber particle size. The cumulative velocity of pore water pressure is significantly slower than that of other samples, especially for the RTM which adds Cr4.

The chart between the liquefaction cycle number and particle size under different rubber particle sizes of the RTM is shown in Figure 8. As the content of rubber particles is $15 \%$, the liquefaction cycle number of rubber particles with the particle size of $0.25 \mathrm{~mm}, 0.85 \mathrm{~mm}, 2 \mathrm{~mm}$, and $4 \mathrm{~mm}$ is 17 , 25,60 , and 56 , respectively. It can be seen that the liquefaction cycle number of the RTM increases rapidly at first and then decreases slowly with the rubber particle size. The area can be divided into parts I and II, as shown in Figure 8. In the particle size range of $0-2 \mathrm{~mm}$-zone I-the liquefaction cycle number of the RTM is basically linear with the particle size of rubber, and the goodness of fit of the linear fitting is 0.944 . When the particle size of rubber exceeds $2 \mathrm{~mm}$-zone II-the liquefaction resistance of the RTM decreases with the rubber particle size. The failure or liquefaction criteria for all tests are taken as the state when the cumulative dynamic strain reaches $10 \%$.

3.2. Effects of Rubber Fraction. The relationship between the rubber content and pore water pressure is shown in Figure 9, and it can be seen that the growth rate of pore water pressure gradually slows down, but the pore water pressure also gradually decreases when it reaches the liquefaction standard with the increase of the mixing amount. In other words, the increase of rubber particle content can reduce the increased rate of pore water pressure and also reduce the value of pore water pressure during liquefaction.

The relationship between rubber content and liquefaction cycle number is shown in Figure 10. The liquefaction resistance of the RTM increases rapidly with rubber content in the range of $0-15 \%$. When the content is more than $15 \%$, the antiliquefaction ability gradually decreases. The fitting formula is $N=0.892+5.223 C-0.125 C^{2}$, and $R$ value reaches 0.987 , which basically conforms to the change law of quadratic parabola. The liquefaction resistance of the RTM increases with the content of rubber particles in a certain range, but the increase rate gradually decreases. When the content of the rubber particle reaches a certain value, the continuous increase of rubber particle content will lead to the decrease of the antiliquefaction ability of the RTM.

3.3. Effects of Confining Pressure. Manipulating multiple groups of data, the average value is taken after removing the data with large variance. The relationship between the consolidation pressure and liquefaction cycle number is shown in Figure 11. The liquefaction cycle number of the RTM samples increases at first and then decreases with the increase of consolidation pressure, which is different from the curve obtained from pure sand by other researchers. The liquefaction cycle number of the RTM sample increases

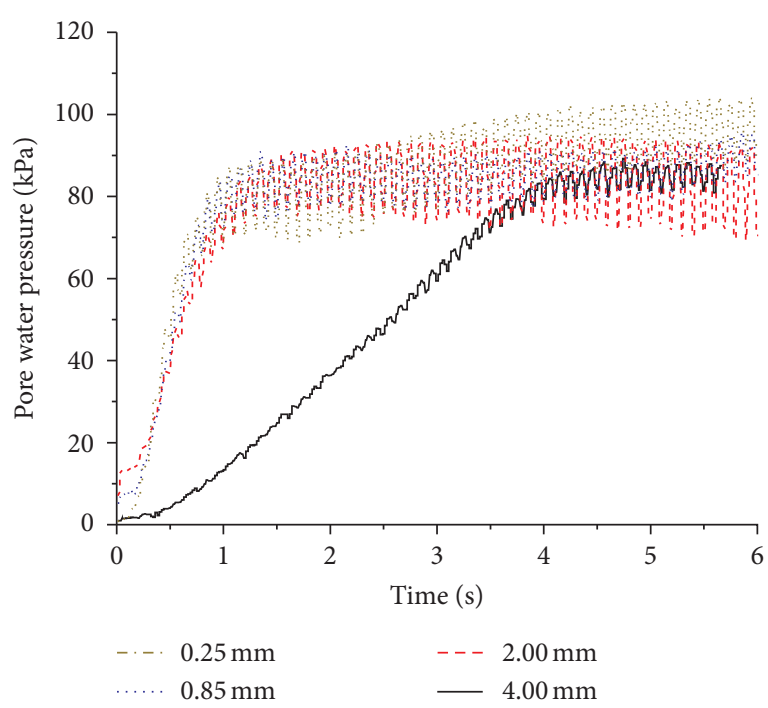

FIgURE 7: The pore pressure diagram-time chart under different rubber particle size.

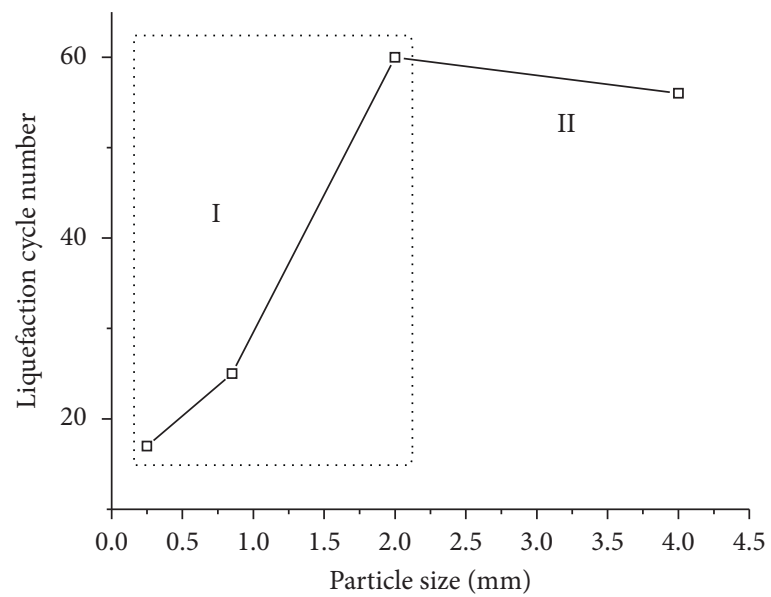

FIgURE 8: The diagram between liquefaction cycle number and particle size.

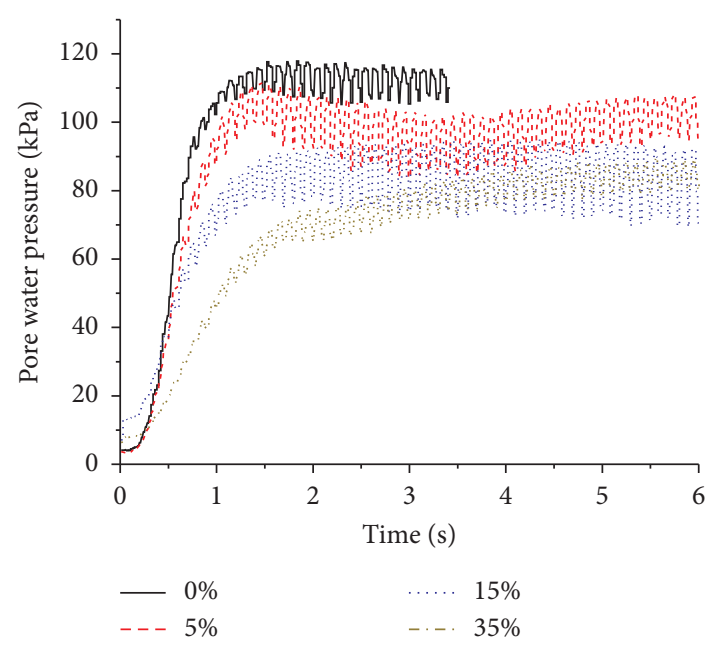

FIGURE 9: The diagram between pore water pressure and time under different mixing amount. 


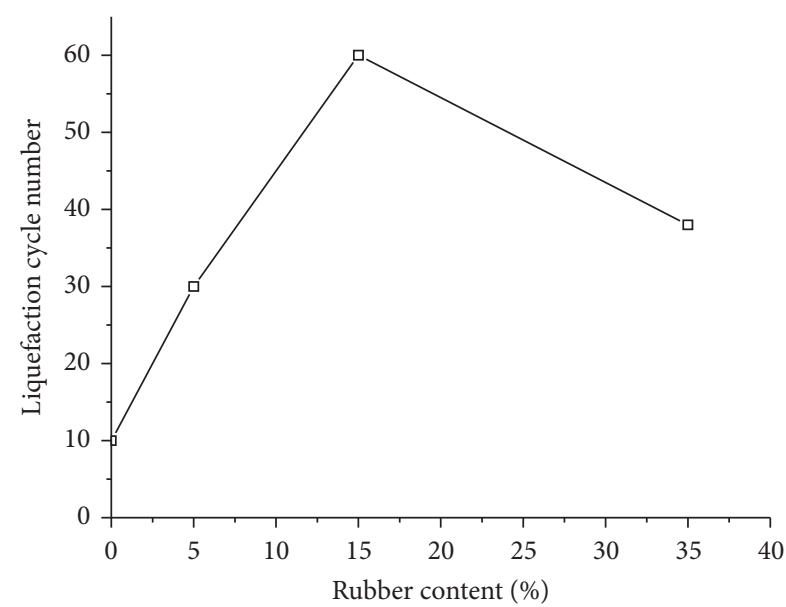

Figure 10: The diagram between the liquefaction cycle number and content of rubber particle.

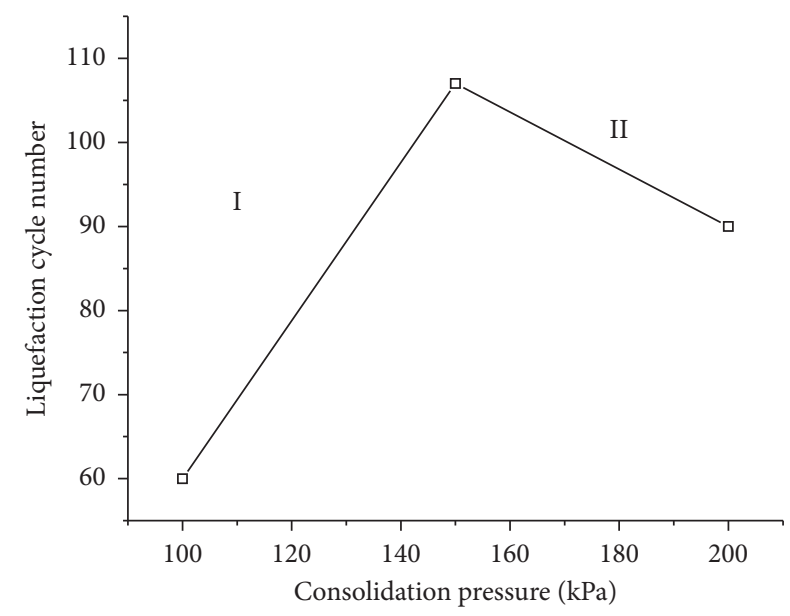

Figure 11: The diagram between the liquefaction cycle number and consolidation pressure.

rapidly in the range of $100-150 \mathrm{kPa}$, while the liquefaction cycle number of the RTM sample decreases in the range of $150-200 \mathrm{kPa}$.

The displacement-time curves under different consolidation pressures are compared, showing a significant difference in stage I of each curve, as shown in Figure 12. Compared with the displacement-time diagrams in Figure 12 , the time required for stage I increases significantly with the consolidation pressure. It indicates that the time required for stage II and stage III is significantly reduced by comparing the displacement-time diagram under $150 \mathrm{kPa}$ and $200 \mathrm{kPa}$ consolidation pressure. Furthermore, the increasing rate of pore water pressure also shows a significant slowdown with the increase of consolidation pressure, as shown in Figure 13.

3.4. Effects of the pH of the Solution Fraction. Compared with the RTM unsoaked in acid solution, the liquefaction cycle number of the RTM soaked in acid solution is significantly reduced, as shown in Figure 14. The antiliquefaction ability

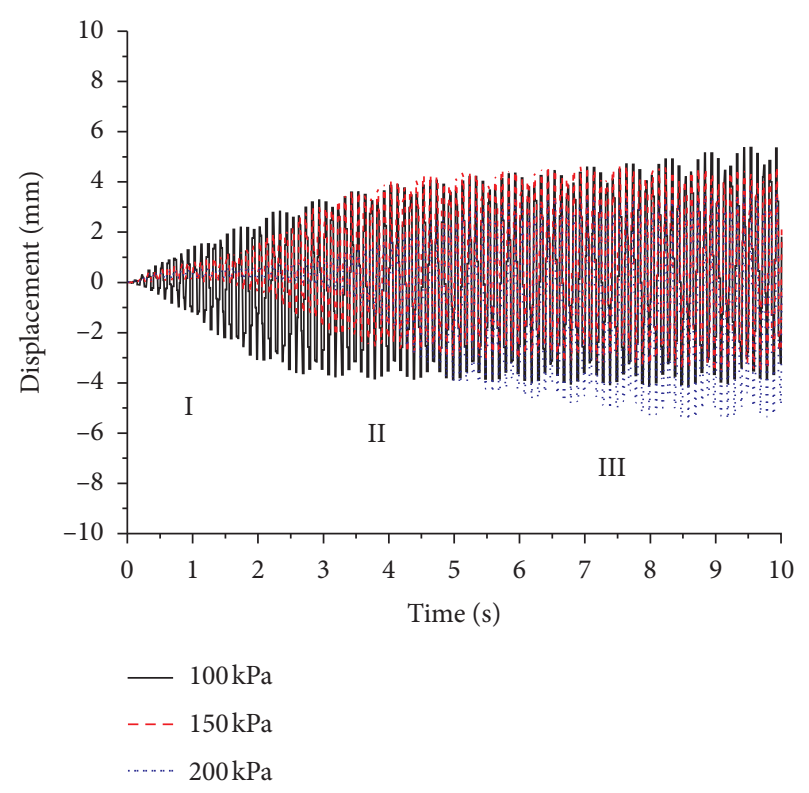

FIgURE 12: The diagram between the displacement and time under different confining pressure.

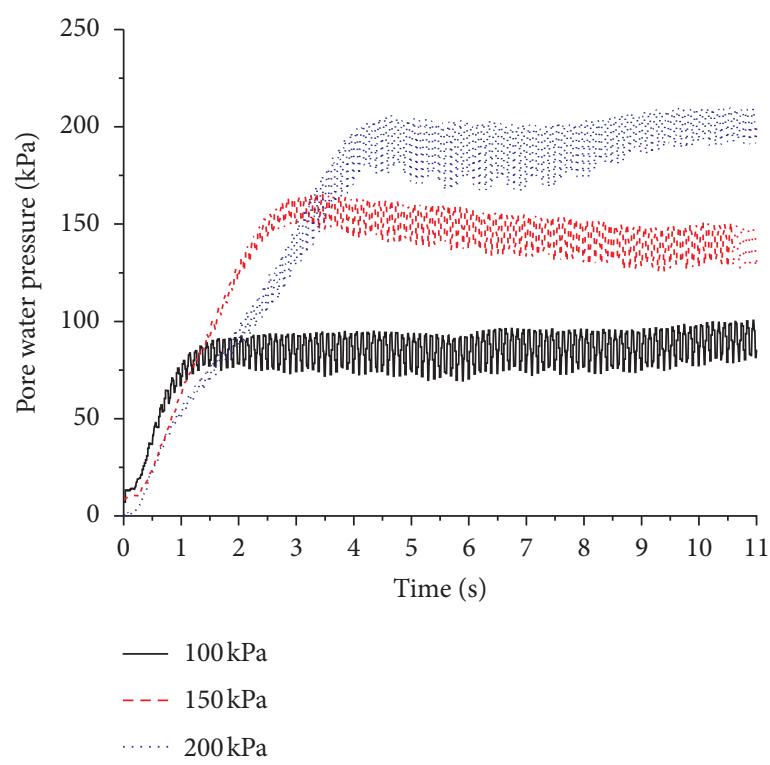

FIGURE 13: The diagram between the pore water pressure and time under different confining pressure.

of RTM decreases rapidly when the $\mathrm{pH}$ value of the soaked solution decreases from 7 to 2 . When the $\mathrm{pH}$ value of the soaked solution continued to decrease, the antiliquefaction ability of the RTM was improved. However, the liquefaction resistance of the RTM is still far lower than that of the RTM without acid soaking treatment.

3.5. Effects of the Acid Treatment Time. Compared with the RTM soaked in water, the liquefaction resistance of the RTM decreases significantly, and the liquefaction resistance of the RTM with both types is obviously higher than that of the pure tailings. When the soaking time is extended 


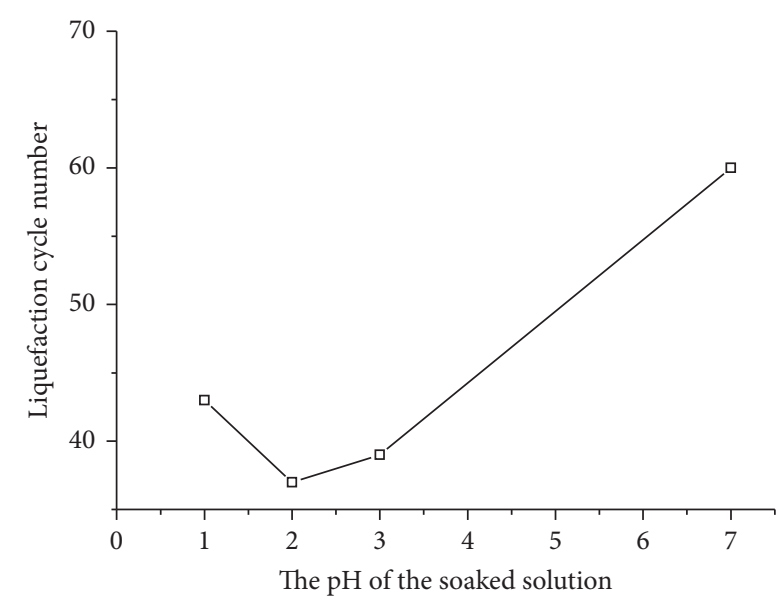

FIgURE 14: The relationship between the liquefaction cycle number and $\mathrm{pH}$ value of soaked solution after 28 days.

from 3 days to 28 days, the change of liquefaction cycle times is not more than $10 \%$ and the change is not obvious, as shown in Figure 15. The results show that most rubber particles have been corroded after soaking in sulfuric acid solution with $\mathrm{pH}=2$ for 3 days. Magnifying the broken line at 3-28 days, the broken line rises first and then decreases.

\section{Discussion}

4.1. Particle Size Variable. When some small particles gather together due to the force between the particles, they play the role of large particles in the sample, which is called the particle cluster effect. In this experiment, the volume of rubber particles with a large particle size is much larger than that of tailings particles, and the surface is uneven with a large number of convex and concave shape. Due to the low compression modulus of rubber particles, the convex shape of rubber particles will deform subjecting to external actions, consolidation stress and dynamic load, which will increase the contact effect on tailings particles and even produce the wrapping effect. When rubber particles contact with tailings, the rubber particles will become the core, and the tailings will be wrapped to form larger particle clusters, which will produce the particle cluster effect and improve its liquefaction resistance. When the rubber particle size is small, the convex and concave regions on the surface of rubber particles are small, weakening the binding effect on tailings particles and the particle cluster effect. The effective restraint of rubber particles by the convex and concave region of rubber particles is gradually enhanced, and the particle cluster effect is also gradually enhanced with the increase of rubber particle size. When the rubber particles are large, the ratio of surface to volume decreases with the increase of rubber particle size, although the convex and concave regions of rubber particles can effectively restrain the tailings particles. When the rubber particles have the same content, the surface area of large-size rubber particles is smaller, whose particle cluster effect is not as good as that of medium-size rubber particles, as shown in Figure 16.

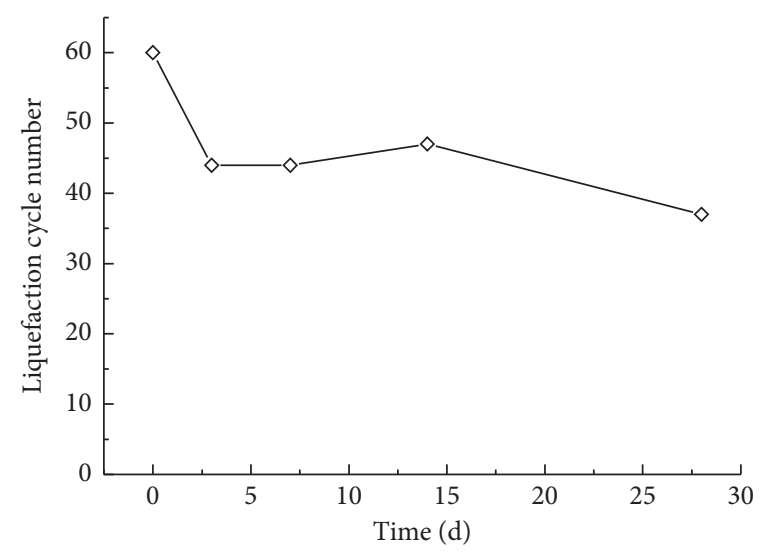

FIgURE 15: The diagram between the liquefaction cycle number and the soaked time of acid treatment.

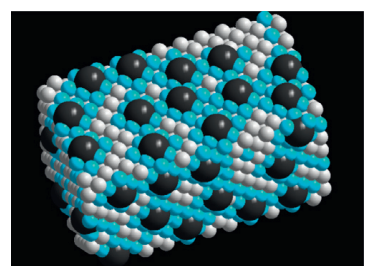

(a)

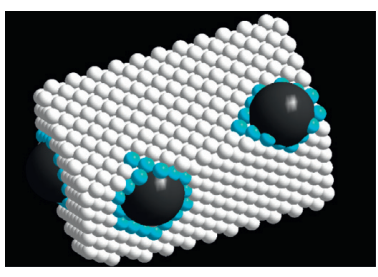

(b)
FIgURE 16: The effect diagram of rubber particles with different particle sizes. (a) The effect diagram of small rubber particles in the RTM. (b) The effect diagram of large rubber particles in the RTM.

The influence of small rubber particles on the permeability coefficient of the RTM cannot be ignored. Extruded by the external force, the rubber particles will produce elastic deformation due to the large compressibility and block the drainage channel. Compared with ordinary tailings, the powder of fine rubber particles has the effect of filling the gap of particles because of the small particle size and reduces its permeability coefficient, which weakens the liquefaction resistance of the RTM. The effect of fine rubber particles in the RTM is similar to that of silt or clay in the sand [31]. Sladen et al. [32] found that the compressibility of sandmixed large amounts of fine-grained sand would be improved and the permeability coefficient would be reduced under the constant external load through experimental analysis.

The large rubber particles can significantly improve the drainage channel of the RTM. According to the research of $\mathrm{Li}$ et al. [33], adding rubber particles with larger size into the standard sand can strengthen the particle cluster effect, increase the permeability coefficient, and improve the liquefaction resistance. When the dynamic stress acts on the sample, the pore water pressure generated is uneven in all parts of the sample, and seepage will occur in the soil, which will induce seepage liquefaction. The addition of rubber particles can improve the internal drainage conditions of soil, optimize the drainage channel, and reduce the influence of dynamic load on seepage liquefaction. 
In general, the fine particles will not be evenly distributed in the sample and will form a layer or block of fine particles. Seid-Karbasi and Byrne [34] studied the effect of fine particle layer on the liquefaction resistance of sand in the experiment of pore redistribution. It was found that the fine particle layer can destroy the particle structure among sand particles by hindering the dissipation of excess pore water pressure and thus lead to the destruction of the stability of the sample in the liquefaction process. In practical engineering, the RTM may be used as reinforced building materials to improve the antiliquefaction performance of building materials. The mixture must be fully mixed evenly, avoiding the powder of fine rubber to form a layered structure, which will reduce the permeability coefficient of the RTM and eventually weaken its antiliquefaction ability.

The results show that the effect of fine-grained rubber in the RTM is not obvious and cannot increase the permeability coefficient. However, the antiliquefaction coefficient of the sample is still significantly improved due to the energy absorption of rubber particles. The high damping rubber is a kind of polymer formed by macromolecular chain segments, which are irregular and tortuous. When the external work is done, the polymer has a relative displacement. The internal friction force can change the external work into heat energy, showing the characteristics of energy absorption for the rubber particles [35]. When the RTM is subjected to dynamic load, the rubber particles are compressed and deformed. Due to the internal friction force, the polymer will change the load into heat energy and dissipate part of the external force because of energy absorption characteristics, which improve the antiliquefaction ability of tailings. The energy absorption of rubber particles is only related to the percentage of the rubber particles and has no obvious relationship with the particle size.

In short, the influence of rubber particle size on the liquefaction resistance of the RTM is particle cluster effect, increasing drainage channel and energy absorption effect. The particle cluster effect of rubber particles with medium particle size is the most obvious under the same content of rubble particles. Small rubber particles decrease the permeability coefficient of the RTM, while large rubber particles increase the permeability coefficient of the RTM. The energy absorption of rubber particles is only related to the content of rubble particles and is independent of particle size. Therefore, the antiliquefaction performance of the RTM needs to select rubber particles with different particle sizes as additives according to the specific requirements in practical engineering.

4.2. Content Variable. Under the same size of rubber particles, the aggregate formed by the rubber particles and tailings increases with the content of rubber particles, which indicates that the content of coarse aggregate in the RTM increases. Due to the fact that the size of rubber particles is larger than tailings particles, the permeability coefficient increases and the antiliquefaction ability is enhanced considering the particle cluster effect. However, when the content of rubber particles increases to a certain extent, the particle cluster effect will also reach its limitation, which has an upper limit on the antiliquefaction capability of the RTM. When the content of rubber particles is too high, the influence areas of different rubber particles overlap each other, as shown in Figure 17. Therefore, the particle cluster effect caused by rubber particles cannot increase the liquefaction resistance further.

The energy absorption effect of the RTM is closely related to the content of rubber particles. The proportion of rubber area on the same cross section also increases with the rubber content, and the energy absorption effect of the rubber is more obvious. However, a too high amount of rubber particles will affect the compression properties of the RTM. Due to the low density of rubber itself and the high modulus of resilience, the rubber particles are deformed greatly after compression under the same compaction condition, and the rubber particles rebound after the load is removed.

The compression modulus of rubber particles is much lower than that of tailings. When the RTM specimen is compressed under load, the rubber particles will have greater compression deformation. When the rubber particle content in the specimen is too high, the main stress frame of the specimen is made of rubber, and it is easy to cause large displacement under compression, which makes the geotechnical structure not to meet the limit state of normal use due to excessive deformation.

4.3. Confining Pressure Variable. In the range of Section 1, the contact of tailings to tailings and rubber to rubber and a small amount of rubber to rubber are more closely with the increase of confining pressure. Due to the particle cluster effect, the size and quantity of large particle clusters increase, leading to an increase of the liquefaction resistance.

In the range of Section 2, the compression amount of rubber particles increases with the confining pressure. The relationship between the compression amount of rubber particles and the required force is $L=k x^{2}$. When force $F_{1}$ acts on the rubber block, the displacement $X_{1}$ is produced. The added force $F_{2}$ acts based on $F_{1}$, and the total displacement is $X_{1}+X_{2}$. When force $F_{1}$ is larger, the displacement $X_{2}$ produced by the same $F_{2}$ is smaller. In terms of energy absorption effect of rubber, the smaller the displacement is, the lower the heat generated by the friction of rubber particles is, which indicates that the energy absorption effect of rubber particles has a close relationship with displacement. When the consolidation pressure increases, the particle clusters formed by the particle cluster effect are more compact and larger. However, the density increase of particle clusters does not increase the liquefaction resistance of the sample, as the confining pressure increases. Because of the limitation of the rubber surface area, the size of particle clusters also reaches its upper limit. Considering the above two reasons, the liquefaction resistance of RTM cannot increase linearly with the confining pressure.

4.4. Acid Treatment Time Variable. The rubber particles unsoaked in acid solution have a smooth surface and airtight and flat. When the rubber particles are soaked in the acid solution for 3-7 days, some cavities appear on the surface of 


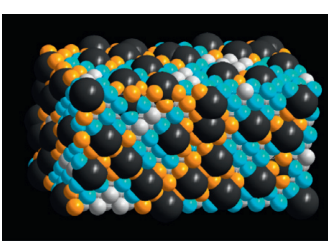

(a)

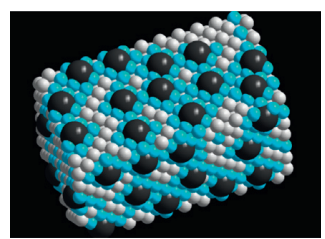

(b)
FIgURE 17: The schematic diagram of rubber particles with different contents. (a) The schematic diagram of high content rubber particles. (b) The schematic diagram of proper content of rubber particles. Note: the orange position indicates the overlapping area of particle cluster effect.

rubber particles. After soaking for 14 days, the cavity of rubber particles is further reduced and the dense structure is exposed. The number of holes is basically the same after 28 days, and the size of rubber particles becomes slightly small.

4.5. The $p H$ Value of the Solution Fraction Variable. The concentration of hydrogen ion provided by acid solution with $\mathrm{pH}=2$ is higher than that with $\mathrm{pH}=3$. The effects of two rubber particles on tailings are very similar after soaking for 28 days. The reason may be that the concentration of hydrogen ion provided by the two solutions is enough to meet the demand for rubber reaction. However, the antiliquefaction ability of the RTM is slightly improved by soaking rubber particles in the acid solution with $\mathrm{pH}=1$. The reason may be that the acid solution with $\mathrm{pH}=1$ has stronger oxidation, which makes rubber particles oxidize and changes the physical properties.

\section{Conclusions and Recommendations}

Based on the dynamic triaxial test of the RTM, the influence of different factors on its dynamic performance was studied.

(1) Under the same content of rubber particle, the liquefaction resistance of the RTM samples increases at first and then decreases with the increase of particle size.

(2) On the premise of unchanged rubber particle size, the liquefaction resistance of the RTM samples increases first and then decreases with the increase of particle content, which is in line with the quadratic parabolic law.

(3) Assuming that the components in the specimen remain unchanged, the liquefaction resistance of the RTM samples increases first and then decreases with the increase of consolidation pressure.

(4) The antiliquefaction properties of the RTM samples soaked in different $\mathrm{pH}$ value after 28 days are significantly reduced. The liquefaction resistance of the RTM first decreases and then increases with the increase of $\mathrm{pH}$ values. Interestingly, the effect of different $\mathrm{pH}$ value of the soaked solution is similar, and the difference is not significant.

(5) The RTM made by soaking rubber particles in acid solution with $\mathrm{pH}=2$ for different days increases first and then decreases with the increase of immersion days. The influence of rubber particles with different soaking days on the antiliquefaction performance of tailings is not significant.

(6) The displacement liquefaction curve of RTM is different from that of standard sand, which can be divided into three stages. Stage I is the stable stage, in which there is no large deformation. Stage II is the catastrophe stage, in which the deformation increases sharply and the deformation speed is fast. Stage III is the restabilization stage, in which the deformation is basically stable, the deformation increment is small and the deformation speed is slow.

\section{Data Availability}

The data used to support the findings of this study are included within the article.

\section{Conflicts of Interest}

The authors declare that they have no conflicts of interest.

\section{Acknowledgments}

This paper was supported by the Scientific Research Fund of Institute of Engineering Mechanics, China Earthquake Administration (Grant no. 2020EEEVL0204), the National Key Research and Development Program of China (Project no. 2017YFC0804601), the National Natural Science Foundation of China (Grant nos. 51764020, 41967035, and U1802243), and the General Projects of Yunnan Province (Grant no. 202001AT070083). The authors would like to acknowledge them for providing financial support for conducting this research.

\section{References}

[1] J. Jin, Y. Li, H. Cui, X. Zhang, X. Xiao, and X. Lv, "Experimental study on the liquefaction characteristics of tailing sand under earthquake action and establishment of flow model," Arabian Journal of Geosciences, vol. 13, no. 14, 2020.

[2] H. J. Wang, "Analysis on the present situation of mineral resources conservation and comprehensive utilization in China," Conservation and Utilization of Mineral Resources, vol. 12, no. 2, pp. 1-5, 2017, in Chinese.

[3] L. L. Liu, G. J. Cai, J. Zhang, X. Y. Liu, and K. Liu, "Evaluation of engineering properties and environmental effect of recycled waste tire-sand/soil in geotechnical engineering: a compressive review," Renewable and Sustainable Energy Reviews, vol. 126, 2020.

[4] Q. L. Wang, Study on the Fragmentation of Waste Tire by Cold Quenching after Low Temperature Pyrolysis, Tianjin University School of Environment Science and Engineering, Tianjin, China, 2007, in Chinese.

[5] G. X. Xi, W. J. Yang, and M. X. Lu, "New progress of waste tire recycling and its use," Chemical Technology Market, vol. 31, no. 9, pp. 1-6, 2008, in Chinese.

[6] W. H. Han, F. Horka, and G. B. Mckenna, "Mechanical and swelling behaviors of rubber: a comparison of some molecular 
models with experiment," Mathematics and Mechanics of Solids, vol. 4, no. 2, pp. 139-167, 1999.

[7] T. Edeskar, "Use of Tire Shreds in Civil Engineering Applications: Technical and Environmental Properties, Lulea University of Technology, Lulea, Sweden, UK, 2006.

[8] J. H. Lee, R. Salgado, A. Bernal, and C. W. Lovell, "Shredded tires and rubber-sand as lightweight backfill," Journal of Geotechnical and Geoenvironmental Engineering, vol. 125, no. 2, pp. 132-141, 1999.

[9] Z. Y. Wang, N. Zhang, Q. Li, and X. H. Chen, "Dynamic response of bridge abutment to sand-rubber mixtures backfill under seismic loading conditions," Journal of Vibroengineering, vol. 19, no. 1, pp. 434-446, 2017.

[10] T. B. Edil and P. J. Bosscher, "Engineering properties of tire chips and soil mixtures," Geotechnical Testing Journal, vol. 17, no. 4, pp. 453-464, 1994.

[11] C. F. S. A. Cristine, Behaviour of Gravity Retaining Wall Using Scrap Tires, Puc-Rio in collaboration with University of Ottawa and Geo-Rio, Rio de Janeiro, Brazil, 1996.

[12] T. S. N. Moghaddas and A. H. Norouzi, "Bearing capacity of a square model footing on sand reinforced with shredded tire: an experimental investigation," Construction and Building Materials, vol. 35, pp. 547-556, 2012.

[13] A. Panjamani and D. R. Manohar, "Shear Strength Characteristics and Static Response of Sand-Tire Crumb Mixtures for Seismic Isolation," Kandy, Sri Lanka, ICSBE-2012, in Proceedings of the International Conference on Sustainable Built Environment, Yogyakarta, Indonesia, June 2013.

[14] S. Pamukcu and S. Akbulut, "Thermoelastic enhancement of damping of sand using synthetic ground rubber," Journal of Geotechnical and Geoenvironmental Engineering, vol. 132, no. 4, pp. 501-510, 2006.

[15] A. Marto, M. R. Jahidin, N. A. Aziz, F. Kasim, and N. Z. Mohd, "Stabilization of marine clay using biomass silica-rubber chips mixture," IOP Conference Series: Materials Science and Engineering, vol. 160, p. 012084, 2016.

[16] A. M. Abdelhaleem and H. Lotfy, Evaluation of Rubber/sand Mixtures as Replacement Soils to Mitigate Earthquake Induced Ground Motions, pp. 3163-3166, Soil Mechanics and Geotechnical Engineering, London, UK, 2013.

[17] H. Hazarika, E. Kohama, and T. Sugano, "Underwater shake table tests on waterfront structures protected with tire chips cushion," Journal of Geotechnical and Geoenvironmental Engineering, vol. 134, no. 12, pp. 1706-1719, 2008.

[18] D. V. Okur and S. U. Umu, "Dynamic properties of clean sand modified with granulated rubber," Advances in Civil Engineering, vol. 2018, p. 1, 2018.

[19] K. Senetakis, A. Anastasiadis, K. Pitilakis, A. Souli, T. Edil, and S. W. Dean, "Dynamic behavior of sand/rubber mixtures, Part II: effect of rubber content on G/GO- $\gamma$-DT curves and volumetric threshold strain," Journal of ASTM International, vol. 9, no. 2, Article ID 103711, 2012.

[20] A. Anastasiadis, K. Senetakis, and K. Pitilakis, "Small-strain shear modulus and damping ratio of sand-rubber and gravelrubber mixtures," Geotechnical and Geological Engineering, vol. 30, no. 2, pp. 363-382, 2012.

[21] A. Anastasiadis, K. Pitilakis, and K. Senetakis, "Dynamic shear modulus and damping ratio curves of sand/rubber mixtures," in Proceedings of the Earthquake Geotechnical Engineering Satellite Conference, XVIIth International Conference on Soil Mechanics and Geotechnical Engineering, IOS Press, pp. 29-34, Alexandria, Egypt, October 2009.

[22] M. Ehsani, N. Shariatmadari, and S. M. Mirhosseini, "Shear modulus and damping ratio of sand-granulated rubber mixtures," Journal of Central South University, vol. 22, no. 8, pp. 3159-3167, 2015.

[23] Y. F. Zheng and K. G. Sutter, "Dynamic properties of granulated rubber/sand mixtures," Geotechnical Testing Journal, vol. 23, no. 3, pp. 338-344, 2000.

[24] H. Bahador and S. Manafi, "Investigation on the dynamic properties of saturated sand-tire chips mixture by shaking table," in Proceedings of the 18th International Conference on Soil Mechanics and Geotechnical Engineering, pp. 883-886, Paris, France, UK, January 2013.

[25] R. S. Ladd, "Preparing test specimens using undercompaction," Geotechnical Testing Journal, vol. 1, no. 1, pp. 16-23, 1978.

[26] S. Q. Peng, Q. H. Zhao, and R. Q. Huang, "The dynamic triaxial study of Chengdu clay," Journal of Geological Hazards and Environment Preservations, vol. 13, no. 1, pp. 57-60, 2002, in Chinese.

[27] J. Zhang, J. Cao, and S. Huang, "Effects of initial shear stress and vibration frequency on the dynamic pore-water pressure of saturated sands," Advances in Civil Engineering, vol. 2018, p. 1, 2018.

[28] Z. Lv, J. G. Qian, Z. H. Shi, and Q. Gao, "Dynamic responses of layered poroelastic ground under moving traffic loads considering effects of pavement roughness," Soil Dynamics and Earthquake Engineering, vol. 130, 2020.

[29] J. M. Zhang and W. X. Wang, "Influence of vibration frequency on dynamic characteristics of saturated sands," Chinese Journal of Geotechnical Engineering, vol. 12, no. 1, pp. 89-97, 1990, in Chinese.

[30] Z. Lu, R. Fang, H. L. Yao, Z. Hu, and J. Liu, "Evaluation and analysis of the traffic load-induced settlement of roads on soft subsoils with low embankments," International Journal of Geomechanics, vol. 18, no. 6, Article ID 04018043, 2018.

[31] B. Li and M. Huang, "Dynamic triaxial experimental study on liquefaction characteristics of sand mixed with rubber powder," Rock and Soil Mechanics, vol. 38, no. 5, pp. 1343-1348, 2017, in Chinese.

[32] J. A. Sladen, R. D. D'Hollander, and J. Krahn, "The liquefaction of sands, a collapse surface approach," Canadian Geotechnical Journal, vol. 22, no. 4, pp. 564-578, 1985.

[33] B. Li, M. Huang, and X. Zeng, "Dynamic behavior and liquefaction analysis of recycled-rubber sand mixtures," Journal of Materials in Civil Engineering, vol. 28, no. 11, 2016.

[34] M. Seid-Karbasi and P. M. Byrne, "Seismic liquefaction, lateral spreading, and flow slides: a numerical investigation into void redistribution," Canadian Geotechnical Journal, vol. 44, no. 7, pp. 873-890, 2007.

[35] L. Qiao, M. Zhou, J. M. Yang, and Q. W. Li, "Experimental study on energy absorption of high damping rubber for rock under dynamic loads," Chinese Journal of Rock Mechanics and Engineering, vol. 37, no. 4, pp. 961-968, 2018, in Chinese. 